\title{
Cyberspace - Addiction or Not: A Limited Case Study of the Internet Addiction among Student Population
}

Slađana Živković

Technical College of Vocational studies \& Faculty of Civil Engineering and Architecture University of Niš, Serbia

\section{Nadežda Stojković}

Faculty of Electrical Engineering, University of Niš, Serbia

Doi:10.5901/ajis.2013.v2n11p150

\section{Abstract}

The paper presents an investigation into the role and relevance of computers and the Internet among young population, the aim of the usage of the virtual network, the time spent in cyberspace, as well as the Internet addiction. For the purpose of this investigation a questionnarie was used. The obtained results led to significant conclusions. Investigation results were statistically processed and shown in tables, to be followed by a discussion on the directions on further research that would include psycholology, sociology and sociolinguistics. The authors emphasise the need for a multidisciplinarian approach to this phenomenon.

Keywords: computer, Internet addiction, investigation, questionnaire, multidisciplinary.

\section{Introduction - On the Presence and Relevance of Contemporary Technologies}

The term contemporary technologies refers to a type of technology that allows access to and fast exchange of all kinds of information and distance communication. The real revolution in this area happened at the end of $80 \mathrm{~s}$ of $20^{\text {th }}$ century with the introduction of the global computer network - the Internet, which has become one of the most available media, and which represents the most frequently used type of technology of today. The Internet is a highly relevant, revolutionary invention, an extremely dynamic area ${ }^{1}$, and it is a fact that today, cyberspace dominates our lives. That is an interactive space that does not represent only technological, but social revolution as well. Howard Rheingold ${ }^{2}$, one of the most outstanding Internet theorists, speaking on digital revolution, claims that the Internet is a contemporary media for communication that connects people in a new, yet unseen way. The number of users of the Internet is in constant growth. Some consider this computer network a source of entertainment, others use it within their professions, for gaining new knowledge or making contacts with other people worldwide. The Internet is of special interest specifically among young population who grow up with the virtual world whose presence today is unavoidable.

Considering the high relevance that the Internet has for life as it is today, there are innumerable investigations into the time spent on the Net. Related to this is the issue of the Internet addiction that most generally can be understood as the overuse of this media to the detriment of some social, psychological, health aspects of human life. Thus, there is much talk on the Internet addiction as a serious socio-psychological-linguistic problem. However, in Serbia, still not enough attention is being paid to this issue. The aim of the authors is to stir interest for the Internet addiction as one of the most acute problems in the world today, but also in Serbia. They will not, however, deal with the social or psychological reasons that commence this type of addiction, but will certainly point to some possible directions of where to find clues as to why this phenomenon is gaining on presence in this country.

\section{The Aim of the Investigation}


The idea for starting Internet addiction investigation resulted from the need to prove that this addiction is a reality, that it is present in everyday life, and that it represents a serious issue, especially among young population. Therefore, the aim of this research is to determine the role and importance of computers and Internet technology among the young, the frequency and aim of the use of the digital network, as well as the existence or absence of existence of the Internet addiction among the student population in Serbia. This problem was approached from the socio-psychological-liguistical point of view.

\subsection{Investigation sample}

The investigation was performed at the Faculty of Civil Engineering and Architecture in Niš, based on the sample of 315 students. Students of all ages (19-23), and from all study groups were questioned. That is the target group which grows up with computers. The collecting of data was done in the spring semester, March 2013. The data thus obtained are used solely for scientific purposes.

\subsection{The technique used for collecting data}

The investigation was performed with a questionnaire method. The data were processed statistically, and the obtained results are shown in tables. The questionnaire comprised two parts. The first part contained questions relating to the use of contemporary technology and the ways of its usage. The other part refers to various possible aspects of online behaviour. Apart from the suggested answers, students were given an option to present their own opinion and comment upon the questions asked.

Remark: It should certainly be noted that it is not possible to perform a complete and thorough sociopshychological-linguistical investigation of the problem, before the very concept of the Internet addiction is clearly and precisely defined. The obtained results are certainly not enough to come to some definite conclusions, yet they can be informative, and can be taken as signs of some basic trends in the behaviour of young population in the cyberspace in Serbia.

\subsection{Investigation results:}

Socio-demographic data

Occupation: student

Age: $19-23$

Year of study: I, II, III, IV

Sex: male/female

Origin-place of residence: South Serbia

\subsubsection{Do you own a computer?}

Table 1. Owning a computer

\begin{tabular}{|c|c|c|}
\hline answer & number of students & percentage \\
\hline yes & 289 & $90,6 \%$ \\
\hline no & 26 & $9,4 \%$ \\
\hline
\end{tabular}

What we started from first in our investigation was determining the number of the questioned students who own a computer. By referring to the table showing the obtained results (table 1), we can conclude that there is a high percent of students who have their own computer, that is $90.6 \%$, while a small number of them, $9.4 \%$ do not have it. The reason for this is primarily the lack of financial support for buying a computer.

\subsubsection{Do you use the Internet?}

Table 2. Using the Internet

\begin{tabular}{|c|c|c|}
\hline answer & number of students & percentage \\
\hline yes & 315 & $100 \%$ \\
\hline no & 0 & $0 \%$ \\
\hline
\end{tabular}


With this we wanted to establish to which degree students use the virtual network. We expected a certain, small number of them to give a negative answer. Yet, we came to surprising information that all of the students asked, 315 of them, use this type of communication.

So, when it comes to the question of using the global computer network, it is clear that students express a high degree of interest. It is widely known that today knowing how to use a computer and the Internet is considered informational literacy. Therefore, another insight that the authors gained from their research is that students in Serbia do possess this, presently considered, one of the basic forms of literacy.

\subsubsection{From which places do you access the Internet?}

Table 3. The possibility of online access from various locations

\begin{tabular}{|l|c|c|}
\hline \multicolumn{1}{|c|}{ answer } & number of students & percentage \\
\hline from home & 228 & $72.4 \%$ \\
\hline from faculty & 14 & $4.4 \%$ \\
\hline from cyber café & 36 & $11.4 \%$ \\
\hline from friend's & 30 & $9.5 \%$ \\
\hline other & 7 & $2.3 \%$ \\
\hline
\end{tabular}

The analysis of the results from table 3 determined that the largest number of students use the Internet from their homes, a total of 228 of the students asked, or $72.4 \%$. The access from home represents an advantage as it subsumes a more private and relaxed environment. Students who do not have access to the virtual world from home go elsewhere so as to connect to the Net. By statistically processing the data we got the result that there is a far smaller percentage of students who use the Internet from locations other than their home.

\subsubsection{Which media do you mostly use for getting the necessary information?}

Table 4. The attitude towards electronic and print media

\begin{tabular}{|l|c|c|}
\hline \multicolumn{1}{|c|}{ answer } & number of students & percentage \\
\hline the Internet & 151 & $47.9 \%$ \\
\hline television & 107 & $33.9 \%$ \\
\hline radio & 5 & $1.6 \%$ \\
\hline print media & 52 & $16.6 \%$ \\
\hline
\end{tabular}

Bearing in mind that the present day generation of the young is far too much exposed to the influence of electronic media, it was expected that the largest number of students would answer that the Internet is the most important way for their obtaining information. On the basis of the data presented in table 4, we can conclude that the Internet is gaining over traditional media. The total number of students asked who use the virtual Network for getting the required information is 152 , which is $47.9 \%$. The second in frequency of usage is television, which, as students comment, does not offer attractive programs at every moment. To this they add that television can be watched via Internet, too. Print media is in the third place. Those are primarily entertaining contents that are read. The least popular is radio that is used by solely $1.6 \%$ of the students. According to the majority of them, radio is an outdated media that is very rarely listened to. David Crystal $^{3}$ speaking on the future of the Internet claims that the Internet is so powerful that it will have an ever larger impact on society and the individual, than earlier inventions like television, print media, radio.

\subsubsection{To which aims do you most frequently use the Internet?}

Table 5. The purpose of using the Internet

\begin{tabular}{l|l|l} 
answer & number of students & percentage \\
\hline
\end{tabular}




\begin{tabular}{|l|c|c|}
\hline entertainment & 120 & $38.1 \%$ \\
\hline education & 40 & $12.7 \%$ \\
\hline for being informed & 48 & $15.2 \%$ \\
\hline for communication & 95 & $30.2 \%$ \\
\hline other & 12 & $3.8 \%$ \\
\hline
\end{tabular}

According to the data from table 5 , we can state that the Internet is above all, a medium that offers various entertaining contents. The largest number of students, 120 , which is $38.1 \%$, answered that they use the Internet for fun. After that is online communication. The virtual network offers the possibility of communicating in real time with persons who are at most various parts of the world. The technology has so advanced that it is possible to establish an audio and video contact, meaning we can talk to and at the same time look at that person. Crystall ${ }^{4}$ has a positive attitude towards online communication, for which he says is a special kind of interaction, and which he terms a third medium (first two being speech and writing). Students, on their part, say that virtual network offers a greater amount of freedom in communicating than real communication.

This the authors found to be a highly informative clue as to why the Internet communication is so present, thus appealing to the young. The answer that it gives greater freedom in communicating may be indicative of the social and psychological constraints the students feel imposed upon them. Thus, their tendency to use this media can be seen as their response to those hindrances that the alienated contemporary world presents them with, their rebellion and escape from those.

After online communication there is informing on diverse topics, first of all, on those that are of interest for the young population. The statistics show that a small number of students use the Internet for education, only $12.7 \%$. However, the authors, as university lecturers witness that the interest for using the Internet in educational purposes grows day by day. Students use digital technology for making presentations, seminars, diploma papers, and the like.

\subsubsection{Which type of content on the Internet is of most interest to you?}

Table 6. Content being searched on the Internet

\begin{tabular}{|l|c|c|}
\hline \multicolumn{1}{|c|}{ answer } & number of students & percentage \\
\hline games & 52 & $16.5 \%$ \\
\hline music & 47 & $14.9 \%$ \\
\hline films & 34 & $10.8 \%$ \\
\hline e-mail & 73 & $23.2 \%$ \\
\hline chatting & 31 & $9.8 \%$ \\
\hline newspapers & 23 & $7.3 \%$ \\
\hline advertisements & 30 & $9.5 \%$ \\
\hline shopping & 6 & $1.9 \%$ \\
\hline lottery games & 7 & $2.2 \%$ \\
\hline other & 12 & $3.9 \%$ \\
\hline
\end{tabular}

According to the data from table 6, e-mail is obviously the most frequently used type of activity on the Internet. It is followed by playing numerous kinds of online games, and after that there are music and films which are now available in digital forms. Chatting is also one of widely present activities, and as we can notice, about $10 \%$ of students use it. The table shows that other activities occur in much smaller percentage, that is bellow 10. This question revealed to us once again that the primary reason for accessing the net is fun. For the authors, these trends are informative for the research that is to follow this one. Namely, here we found what areas of the Internet are to be most closely examined when researching the linguistic changes that occur. It is most noticeable that there is a strong and powerful influx of Net terminology in the Serbian language that is directly related to the jargon of entertainment on the Internet.

\subsubsection{For how long have you been using the Internet?}


Table 7. Period of using the virtual network

\begin{tabular}{|l|c|c|}
\hline \multicolumn{1}{|c|}{ answer } & number of students & percentage \\
\hline over 10 years & 3 & $0.9 \%$ \\
\hline 8-10 years & 16 & $5.1 \%$ \\
\hline 5 -8 years & 102 & $32.4 \%$ \\
\hline 3-5 years & 159 & $50.5 \%$ \\
\hline 1-3 years & 35 & $11.1 \%$ \\
\hline less than a year & 0 & $0 \%$ \\
\hline
\end{tabular}

As for the time that has passed since the beginning of students' start of using the Internet, the results from table 7 indicate that the largest number is of those students, about $50 \%$, who have been using the global network for a somewhat longer period, 3-5 years. That is a quite enough period to have gained the necessary knowledge and skills for getting around the cyberspace.

We have here discussed only the crucial data, as the table shows all other.

\subsubsection{Do you use the Internet on a daily basis?}

Table 8. Daily online access

\begin{tabular}{|c|c|c|}
\hline answer & number of students & percentage \\
\hline yes & 289 & $91.7 \%$ \\
\hline no & 26 & $8.3 \%$ \\
\hline
\end{tabular}

Table 8 shows that students use computer network every day at a very high percentage, even $97.1 \%$. There are a small number of them that for some reason do not use the Internet daily. Those reasons can be various: some do not have an online access, have no time because of the duties at the faculty, do not live in the place where they study, etc.

Believing that Internet addiction is to be more closely examined here in Serbia, and that being our starting idea, our small, limited investigation proved the possible need for paying attention to this new kind of psychological disturbance.

\subsubsection{How many hours daily do you spend on the Internet?}

Table 9. Time spent daily in cyberspace

\begin{tabular}{|l|c|c|}
\hline \multicolumn{1}{|c|}{ answer } & number of students & percentage \\
\hline 1 hour & 74 & $23.5 \%$ \\
\hline 2 - 3 hours & 88 & $27.9 \%$ \\
\hline $4-5$ hours & 107 & $33.9 \%$ \\
\hline $6-7$ hours & 17 & $5.4 \%$ \\
\hline $8-9$ hours & 2 & $0.6 \%$ \\
\hline 10 hours & 1 & $0.3 \%$ \\
\hline not daily & 26 & $8.4 \%$ \\
\hline
\end{tabular}

The next issue we wanted to check is the time spent on the net during the day. The rationale for this is more than numerous studies being done on the research and the analysis of the time spent in cyberspace. That research claims that an Internet addict is a person who spends at least 38 hours per week or 8 hours per day on the Internet (Young 1998). Based on the results presented in table 9, we conclude that much time is spent on the Internet, despite duties on the faculty. Those 107 students, or $33.9 \%$ of them, answered that they spend $4-5$ hours online daily. When one comes to think of the usual and expected biorhythm of a student, it is quite justified to ask if they have enough time for all other social activities, as well as for leading a healthy life both in its physical and mental aspect.

\subsubsection{Do you use the Internet as an escape from some problems?}

Table 10. Psycho-social problems as a reason for using the Internet 


\begin{tabular}{|c|c|c|}
\hline answer & number of students & percentage \\
\hline yes & 23 & $8.3 \%$ \\
\hline no & 242 & $75.8 \%$ \\
\hline sometimes & 50 & $15.9 \%$ \\
\hline
\end{tabular}

Judging by the answers of students, we can conclude that a number of those who turn to the web in an attempt to escape certain problems is very low, only $8.3 \%$. A detailed analysis shows that the largest number is of those students who, as they say, have no reason to run away from problems, that number being 242 , or in percentage $-75.8 \%$, while $15.9 \%$ of the students asked answered that they do that from time to time.

By running away from the social reality, individuals search for a way out in a virtual world. An illustration of this could be a fact that Serbia is among the top 20 countries in Europe where Facebook is most widely and frequently used social network ${ }^{5}$. It has been argued that the reasons for this do include problems that have occurred in real social communication due to more than numerous and frequent social, economical and psychological problems. Instead of interacting in real time and space, an enormous number of people turn to social networks instead.

However, the authors find it a happy fact that a young population of students is not in this group of people, and that according to our understanding, they have a preserved sense of social interaction and communication.

\subsubsection{Do you neglect your duties for the Internet?}

Table 11. How often students neglect their duties for being on the Net

\begin{tabular}{|l|c|c|}
\hline \multicolumn{1}{|c|}{ answer } & number of students & percentage \\
\hline all the time & 27 & $8.5 \%$ \\
\hline often & 11 & $3.5 \%$ \\
\hline sometimes & 38 & $12.1 \%$ \\
\hline rarely & 235 & $74.6 \%$ \\
\hline no & 4 & $1.3 \%$ \\
\hline
\end{tabular}

There are studies which showed a close cause and effect link that students who spend a lot 0 time on the net have fewer social contacts, experience sleep disorders, depressive mental states, aggression, all leading to a weaker result at their faculties. This all together can turn into a serious problem.

This question again showed us that students do not overuse the Internet to the expense of their living in real time and space. From this, and from interacting with those students as real personalities with whom we work, thus from knowing them in person, we drew a conclusion that they are truly interested in and oriented to their primary studies, that their vocational science is a lasting source they direct their energy to.

\subsubsection{Does it happen often that you loose a sense of time while searching the Internet?}

Table 12. Selfcontrol in using the Internet

\begin{tabular}{|c|c|c|}
\hline answer & number of students & percentage \\
\hline yes & 36 & $11.4 \%$ \\
\hline no & 234 & $74.3 \%$ \\
\hline sometimes & 45 & $14.3 \%$ \\
\hline
\end{tabular}

Data from table 12 are most encouraging, showing that a large number of students possess enough self control in using the net, the total of 234 , or $74.3 \%$. This again proves our conclusion about the primary attitudes of our students as found in the answer to the previous question. It confirms the fact that those young people consciously and conscientiously chose to be at that particular faculty. 


\subsubsection{How often do you access the Internet for no definite purpose?}

Table 13. Surfing the Internet

\begin{tabular}{|l|c|c|}
\hline \multicolumn{1}{|c|}{ answer } & number of students & percentage \\
\hline all the time & 30 & $9.5 \%$ \\
\hline often & 79 & $25.1 \%$ \\
\hline sometimes & 101 & $32.1 \%$ \\
\hline rarely & 52 & $16.5 \%$ \\
\hline never & 53 & $16.8 \%$ \\
\hline
\end{tabular}

Based on these results, we conclude that the largest number of students, $32.1 \%$, are those who get into the cyberspace without a clear idea of what exactly is being searched (for), while the smallest number is of those who do that regularly, only $9.5 \%$. It is quite clear that the Internet offers huge potential for entertainment, communication, informing.

From the answer to this question and from interviewing students informally about this, the authors found that they turn to the Net with no definite aim in mind as a way of relaxation, trusting, as they claim, that it would lead them by offering intriguing links. Even upon our insisting to clear this attitude for us, and pointing out that surfing for no definite purpose is often a mere and aimless waste of time, they remained firm in their explanation that their surfing the net with no pre set goal of what is being looked for, is simply their way of looking for entertaining and inspiring content. To this they added the excitement of finding the unexpected, the unlooked for information.

\subsubsection{Can you function without the Internet?}

Table 14. Online and offline behavior

\begin{tabular}{|c|c|c|}
\hline answer & number of students & percentage \\
\hline yes & 167 & $52.1 \%$ \\
\hline no & 103 & $33.7 \%$ \\
\hline maybe & 45 & $14.2 \%$ \\
\hline
\end{tabular}

Based on the data presented in this table, it can be said that for the majority of students, somewhat over $50 \%$, the Internet is a necessary media, and that they could not function without at least occasionally visiting the cyberspace. Certain students even reported that they would be depressive and irritable unless they could access the net. As an opposition to this type of attitude is a number of students, $33.7 \%$ of them, who believe that it is absolutely possible to live without the net.

\subsubsection{What is your opinion on the Internet?}

Table 15. Opinion grading of the Internet

\begin{tabular}{|l|c|c|}
\hline \multicolumn{1}{|c|}{ answer } & number of students & percentage \\
\hline highly positive & 101 & $32.1 \%$ \\
\hline positive & 202 & $64.1 \%$ \\
\hline highly negative & 0 & $0 \%$ \\
\hline negative & 12 & $3.8 \%$ \\
\hline
\end{tabular}

This table helps us realize that the majority of students have a positive attitude to the Internet, even $64.1 \%$, as it allows them getting various pieces of information in a fast and straightforward manner, and the new and for them relaxing forms of communication. Again, in an informal argumentation that followed the questionnaire, they explained that this 'Internet speed' and the communication that bears little resemblance to everyday face to face communication, the freedom to express themselves uninhibitedly, is what makes them find this media so appealing. None of the students expressed a strong negative attitude, while a simply negative opinion is with only $3.8 \%$, the reasons for this being psycho-social changes, as they claim. 


\subsubsection{Do you think you have become Internet addicted?}

Table 16. Examining Internet addiction

\begin{tabular}{|c|c|c|}
\hline answer & number of students & percentage \\
\hline yes & 41 & $13 \%$ \\
\hline no & 274 & $87 \%$ \\
\hline
\end{tabular}

The development of contemporary technologies has brought a new phenomenon, Internet addiction that is the overuse of the virtual net. There exist various stances towards this issue, yet still there are no clear criteria that would offer a firm basis for defining the existence or non existence of Internet addiction. Jonathan Bishop ${ }^{6}$, an expert in the field of investigating virtual communities, claims that Internet addiction actually does not exist. He explains that one cannot be addicted to the Internet, as the Internet is a surrounding, and dependence upon surrounding is simply not possible. The Internet is a social medium, and so people can not be Internet addicted.

The results gathered and presented in table 16 show that the majority of the students, 274 of them, or $87 \%$, believe they are not addicted to the net. This allows us to make a wide, general conclusion, that in Serbia, the situation concerning this type of addiction is not yet alarming. There are, however, cases of the clear overuse of the Internet, yet, the authors are of the opinion that this does not represent a threat yet. It is more of a case that Internet addiction is still not a recognized issue and is thus not taken as a serious problem.

\subsubsection{How much has the Internet influenced the changed your language?}

Table 17. The degree of language change under the influence of the Internet?

\begin{tabular}{|l|c|c|}
\hline \multicolumn{1}{|c|}{ answer } & number of students & percentage \\
\hline extremely & 15 & $4.8 \%$ \\
\hline a lot & 120 & $38.1 \%$ \\
\hline considerably & 127 & $40.3 \%$ \\
\hline somewhat & 53 & $16.8 \%$ \\
\hline a little & 0 & $0 \%$ \\
\hline no influence & 0 & $0 \%$ \\
\hline
\end{tabular}

By examining the results from Table 17, it is completely clear that students, by using modern technologies, learn and improve English considerably (40.3\%). Generally speaking, English is the language of the Internet. Language being such a sensitive index of social change, it would be surprising indeed if such a radically innovative phenomenon (as the Internet) did not have a corresponding impact on the way we communicate. And so it can be argued. Language is at the heart of the Internet, for Net activity is interactivity. What is immediately obvious when engaging in any of the Internet's functions is its linguistic character. If the Internet is a revolution, therefore, it is likely to be a linguistic revolution (Crystal 2001).

This was a question of special relevance for the authors. First of all, as this questionnaire was thought of as the first part of the research. The second is the research into exactly this matter - the language change brought about by the use of the Internet. This is a well known fact to laymen, as the examples of the influx of Internet terminology are obvious everywhere and in almost any conversation. However, the authors find that this is of utmost relevance, as this, we believe big language change is related to other phenomena, such as identity changes or shifting.

\section{Discussion}

Internet addiction is a new and variously defined concept. But it can be also said, not yet precisely enough defined. One of the reasons for this is the fact that determining the dynamics of this new phenomenon requires a complex, multidisciplinary approach. The concept of the Internet addiction has appeared relatively recently (Young 1998), and 
primarily refers to the uncontrolled time spent in various Internet activities such as chatting, forums, surfing the net, etc ${ }^{7}$, all of which are believed to have a negative impact on social relations, success at school, work performance, health, and other vital social functions and activities ${ }^{8}$.

We are now going through a period of historic transformation into the so called Informational society. This subsumes creation and adoption of new forms and norms of social communication. The results of this research, although done at a small sample, give encouraging results as they prove the absence of extreme behavior on the Internet. We believe that students, as a representative young, both physically and mentally healthy population exhibit a rational and conscious attitude to this media.

Work with students has led us to do this survey, and consider the results from our own viewpoint. We firmly believe that the obtained results are not only interesting, but also useful. Although limited in scope, this mini research certainly partakes into the depiction of a wide presentation of primarily social profile of this country.

Answers to some questions can provide insight into some psychological, but also linguistical changes brought about with the use of the Internet. The last issue is of special relevance for the authors. Hereby presented research is to be an introduction to the study on the influence of the Internet discourse onto the forming, or changing of identity of young people, namely students. This survey has offered us guidance into what will be the next level of our research.

It has been noted that using the Internet widely, as the students have shown, has to influence the change of linguistic resources of the user. Internet users thus represent one discourse community. That is a community that has its own specifics in relation to the wider linguistic community which is a sociolinguistic term relating to a group of people who use the same dialect variation, or simply one language. Unlike this, a discourse community is determined by functional and sociorethorical characteristics, as all of its users have a common end and use similar rhetorical model. This community is centrifugal, meaning that its members differ from nonmembers, and that those who join this community accept that discourse model ${ }^{9}$.

The question in the survey that is related to the types of content that is searched on the Internet indicated that students are members of different digital communities ${ }^{10}$.

The so called new communities have users ${ }^{11}$, that is members who have common interests and goals, and who are of different nationalities and so speak different languages ${ }^{12}$.

One other characteristic is the use of English language as a lingua franca of the Internet. The consequence of this is the highly recognisable change in the mother tongue towards mere transliteration in the use of terminology, primarily in the area of informational-communicational technologies and the Internet. Those net communities have special, two way research in the area of language, both on the influence of English onto the mother tongue, and vice versa.

\section{Conclusion}

The analysis of the survey conducted at the sample of 315 students we emphasize the importance of the Internet and its presence among the young population, and we also stress the problem of the Internet addiction. We have presented those aspects that we believe to be most informing and representative for this topic.

The questions from the survey cover a large number of areas which was done intentionally so as to give directions for the research that is to follow. It is our belief that standardized questionnaires on online behaviour and communication are a real need that is to be met soon enough by relevant experts.

The interest in cyberworld opens up numerous questions related to the Internet and its influence. Experts are to provide answers to many of the questions raised even in our moderate survey. Those questions being:

Has cyberworld become our reality?

Internet addiction? Or social evolution?

The vanishing line between virtual and real world.

\footnotetext{
${ }^{7}$ King, Storm, 'Is the Internet Addictive, or are Addicts Using the Internet World Wide Web', 1995, http://rdz.stjohns.edu/ storm/iad.html

8 Young, K. S. 'Internet addiction: The emergence of a new clinical disorder'. Paper presented at the 104th annual meeting of the American Psychological Association,. CyberPsychology and Behavior, Vol. 1 No. 3., pages 237-244 Toronto, Canada, August 11, 1998. ${ }^{9}$ Swales, J. M., Genre Analysis: English in Academic and Research Settings, Cambridge, Cambridge University Press, 1990.

10 Goodman, S, \& D. Graddol (eds.), Redesigning English: New Texts, New Identities, London, Routledge, 1996.

${ }_{11}$ Cherny, L., 'Marie Disconnects: third person simple tense in MUD discourse' y Georgetown University Round Table on Languages and Linguistics, Georgetown University Press, 1995.

12 Poster, M., The Mode of Information: poststructuralism and social context, Cambridge, Polity Press, 1990.
} 
Digital identity as a commodity or not?

All this leads to a conclusion that a huge area relating to the Internet remains to be researched. Until then, we are still left with the dilemma: Cyberspace - Addiction or Not?

\section{References}

Bellamy, A., and Hanewicz, C. (1998). Social psychological Dimensions of Electronic Communication'. Electronic Journal of Communication. Volume IV.

Bishop, Jonathan. (2005). 'Does Internet addiction exist?'. Available: http://www.jonathanbishop.com

Cherny, L. (1995). 'Marie Disconnects: third person simple tense in MUD discourse' inGeorgetown University Round Table on Languages and Linguistics. Georgetown University Press.

Crystal, David, (1995). Cambridge Encyclopedia of the English Language. Cambridge. Cambridge University Press.

Crystal, David. (1997). English as a Global Language. Cambridge. Cambridge University Press.

Crystal, David. (2001). Language and the Internet. Cambridge. Cambridge University Press.

Europe Facebook Statistics. Available: http://www.socialbakers.com/countries/continent-detail/europe

Goldberg, I. (1996). 'Internet Addiction'. Available: http://www.cmhc/mlists/research.

Goodman, S, \& D. Graddol (eds.). (1996). Redesigning English: New Texts, New Identities. London. Routledge.

King, Storm. (1995). 'Is the Internet Addictive, or are Addicts Using the Internet World Wide Web'. Available: http://rdz.stjohns.edu | storm/iad.html

Novak, Marcos. (1991). 'Liquid Architectures in Cyberspace'. in Benedikt, p.225. Available: http://www.surfacenoise.info/367/readings Inovak.pdf

Parks, Malcolm. (1990). 'Making Friends in Cyberspace'. Journal of Communication. 46.1.

Poster, M. (1990). The Mode of Information: poststructuralism and social context. Cambridge. Polity Press.

Rheingold, Howard. (1998). The Virtual Community. Available: www.rheingold.com/vc/bookl

Rice, Ronald E. and Gail Love. (1987). 'Electronic Emotion: Socioemotional Content in a Computer-Mediated Communication Network'. Communication Research. 14.1.

Swales, J. M. (1990). Genre Analysis: English in Academic and Research Settings. Cambridge.Cambridge University Press.

Young, K. S. (1998). 'Internet addiction: The emergence of a new clinical disorder'. Paper presented at the 104th annual meeting of the American Psychological Association. CyberPsychology and Behavior. Vol. 1 No. 3. pp. 237-244. Toronto. Canada. August 11. 